\title{
URBAN CROWDSOURCED LAST MILE DELIVERY: MODE OF TRANSPORT EFFECTS ON FLEET PERFORMANCE
}

\author{
Dupljanin, D.; Mirkovic, M.; Dumnic, S.; Culibrk, D.; Milisavljevic, S. \& Sarac, D. \\ Faculty of Technical Sciences, Trg Dositeja Obradovica 6, 21000 Novi Sad, Serbia \\ E-Mail: ddjordji@uns.ac.rs,mmirkov@uns.ac.rs,dumnic.s@uns.ac.rs, dculibrk@uns.ac.rs, \\ steva@uns.ac.rs,dsarac@uns.ac.rs
}

\begin{abstract}
Minimizing last mile delivery costs is of paramount importance for all shipping companies that strive to stay competitive on the market. A potential solution to the problem is the use of crowdsourcing - a model where individuals voluntarily take on a task proposed by another entity (e.g. a company). In this paper, we present the results of a comparison of performance for three types of crowdsourced delivery fleets likely to be used in an urban setting. The fleets differ in the mode of transport the couriers use: bicycles, cars or both. The performance is quantified by the total number of deliveries made and the on-time delivery rates. Experimental results were obtained through a simulation that closely resembles real-world traffic conditions in a city with developed cycling infrastructure and takes into account the variations in the speed of couriers. The research shows that bicycle-based crowdsourced fleets outperform other kinds of fleets under simulated conditions. This makes them a faster, more environmentally-friendly and potentially cheaper alternative to traditional fleets that rely on cars.

(Received in March 2019, accepted in August 2019. This paper was with the authors 2 weeks for 1 revision.)
\end{abstract}

Key Words: Logistics, Urban Delivery, Last Mile Delivery, Crowdsourcing, Simulation Modelling, Performance Analysis

\section{INTRODUCTION}

In traditional shipping, the last mile delivery problem refers to the inefficiency of the final leg of shipment, which ends with a package arriving to the customer's doorstep. This last step of the journey is the most expensive and the most time-consuming one and is slowed down by either long distances between stops in rural areas or heavy traffic in urban settings. A lot of research effort, typically in the form of theoretical proposals and analytical solutions, has been put into devising ways to optimize vehicle routing [1-3], design transport networks [4] and make last-mile deliveries more sustainable [5-7], all aiming to contribute to the reduction of the cost of this final step in the delivery process and make it more environmentallyfriendly. Given the evidence that as much as $88 \%$ of consumers globally are willing to pay for the same day (or faster) delivery [8], the focus of major companies in retail/sales (e.g. Amazon, Google, eBay) and shipping (e.g. DHL, FedEx) domains on making their last-mile operations more efficient (especially in heavily populated urban areas) [9] should not come as a surprise. One of recently proposed solutions to many of the problems pertinent to the last mile delivery is crowdsourcing.

Crowdsourcing can be defined as a type of participative activity in which an individual, an institution, or a company proposes to a group of individuals of varying knowledge, heterogeneity, and number, via a flexible open call, the voluntary undertaking of a task [10]. Even though the term was coined relatively recently and the phenomenon had not been extensively studied in the past as such [11], the approach had been used historically to help with various endeavours, such as compiling a dictionary, searching for extra-terrestrial intelligence, proposing architectural solutions or creating one of the most comprehensive public encyclopaedias to date. However, coupled with modern technological advances and willingness of end-users to become active participants on the provider side in areas traditionally reserved for big corporations, this approach has shown great potential to be 
disruptive to established business models. E.g., Uber and Lyft have become common replacements for traditional taxi services [12] and Amazon's Mechanical Turk offers a marketplace that makes it easier for individuals and businesses to outsource their processes and jobs to a distributed workforce who can perform these tasks virtually [13].

Crowdsourcing systems inherently bear a great amount of uncertainty, given that participants are free to engage in activities as they please. This makes simulations a good approach for the modelling and assessment of performance of such systems under different conditions, as the models allow for studying the problem at hand at different levels of abstraction. Working at higher levels of abstraction allows simulation designers to understand the behaviours and interactions of all the high-level components within the system better, but might at the same time provide a false sense of security regarding the accuracy of the simulation results [14]. High-levels of abstraction are quite common when simulating crowdsourced delivery systems, due to the need to reduce the complexity of simulations. E.g., Manhattan distance is often used to express the proximity between two points (origin and destination of delivery) and a constant speed of actors (i.e. couriers or delivery vehicles) in the system is assumed [15].

Significant research challenges remain in the domain of efficiency assessment of crowdsourced last-mile delivery systems, such as: optimizing the fleet size of crowdsourced and mixed fleets [16], determining the suitability of crowdsourced last-mile delivery for different cities and developing a better understanding of the motivations of crowdsourced drivers [17]. Deriving insights into performance of the crowdsourced delivery systems that resemble real-world conditions as much as possible remains of the utmost importance, which is what we strive to contribute to in this research. In particular, to the best of our knowledge, this is the first study to examine the logistic effectiveness of a delivery system, which relies purely on crowdsourced bicycle couriers and compares it with mixed fleets incorporating both cars and bicycles and those relying purely on cars, in the setting of a modern metropolis.

\section{PROBLEM DEFINITION}

The problem this research focuses on is that of the comparison of logistics effectiveness between different kinds of crowdsourced fleets for the last mile delivery. We do so by taking into account major factors that have been shown to affect it significantly: organizational design, organizational task environment and mode of transport used by couriers.

Logistics effectiveness, which is often measured by Key Performance Indicators (KPIs), such as on-time delivery rate, order accuracy rate and lead times, is one of the key concerns for any company providing delivery services and has been demonstrated to be positively correlated with the overall company performance [18]. Most salient indicators for measuring logistics effectiveness of courier companies that we focus on in this paper are total deliveries made and on-time delivery rate.

A multitude of factors may affect these KPIs, depending on the organizational design of the company and the dynamics pertinent to the organizational task environment. In terms of the organizational design, this research focuses on the scenario in which only a fleet of crowdsourced couriers is available, as opposed to the traditional settings where a company owns a dedicated fleet of vehicles, or hybrid scenarios where a number of dedicated vehicles exists on top of which a number of crowdsourced drivers are hired to help dampen the effects of spikes in delivery requests. In addition, different modes of transportation that this crowdsourced fleet utilizes are considered: fleets comprised exclusively of cars, bicycles and a mixed fleet (a mix of cars and bicycles in equal proportion).

In terms of the dynamics pertinent to the organizational task environment, we study the case of a company that offers same-day delivery services (a choice justified by the findings that customers are willing to pay premium fees for express delivery [8]). 
Two important aspects of the organizational task environment have been identified in previous studies that may affect the couriers' abilities to provide same-day delivery services: time windows for deliveries and dynamic demand fluctuations [19-22]. Time windows for deliveries refer to the levels of service courier companies typically offer for same-day deliveries. Literature review and publicly available data (e.g. Amazon Prime) have shown that most commonly offered (and studied) time windows for same-day delivery are 1, 2 and 4 hours. In addition, we also consider the 8-hour delivery window that should reflect the case where a package is expected within the same day without a rush.

Dynamic demand fluctuations represent the changes in requests for package delivery throughout the day, i.e. number of incoming orders at different points in time (morning until evening). These are commonly modelled as a Poisson process, with intensity parameters derived by consulting domain experts (i.e. industry practitioners) or from previous similar studies.

We formalize and test two hypotheses in the present study:

- H1: There are significant differences in fleet logistics' effectiveness between bicycle, car and mixed crowdsourced fleets that depend on demand fluctuations.

- H2: There are significant differences in fleet logistics' effectiveness between bicycle, car and mixed crowdsourced fleets that depend on the levels of services offered (i.e. time windows for deliveries).

\section{METHODOLOGY}

We adopted the methodology proposed by Castillo et al. [15], which we extended to be able to take into account variable speed of drivers through the customer network, different transportation modes of delivery fleets and one additional level of the independent variable.

Just like Castillo et al., we consider an intra-city courier service providing same-day delivery from a centralized distribution centre in an urban customer network. To simulate the customer network, we obtained addresses of 765 businesses within the Copenhagen area (from a public directory), which serve as destination points for parcels dispatched from the central distribution centre (Fig. 1). Since we consider multiple transportation modes, Copenhagen made a logical choice for a city to base the simulation on, since it ranks very highly in terms of bicycling infrastructure and nearly half of intra-city trips are made by using this mode of transport [23].

Order locations are unknown a priori and arrive dynamically and stochastically throughout the day, thus emulating real-world same-day delivery services. Vehicle accidents or breakdowns are not included in the model and driver diversions are not allowed (i.e. once accepting the delivery task, a driver cannot be diverted to make another pickup and delivery). All delivery requests are accepted, packages are assumed to be small parcels (deliverable by both cars and bicycles) and only one package is delivered per trip.

Unlike previous studies where drivers travel throughout the customer network at a constant speed, we also take into account real-world traffic conditions when calculating the speed of couriers. To do this, we leverage Google Directions - a service that provides trafficconditions adjusted travel times between locations for different transportation modes and during distinct times of a given day. This means that the estimated travel time between two addresses might not be the same if one is traveling at 7:30 am or 10:15 pm, or if one is using a car or a bicycle.

For each destination address, we first query the service to obtain distances and estimated travel times when using a car at $8 \mathrm{am}, 12 \mathrm{am}$ and $7 \mathrm{pm}$ for every workday of the week (Monday through Friday). We divide the two values to obtain the average speed (in $\mathrm{km} / \mathrm{min}$ ) when moving through the city at those particular hours by using this transportation mode. These speeds are then mapped to four distinct intervals for each day in the following manner: 


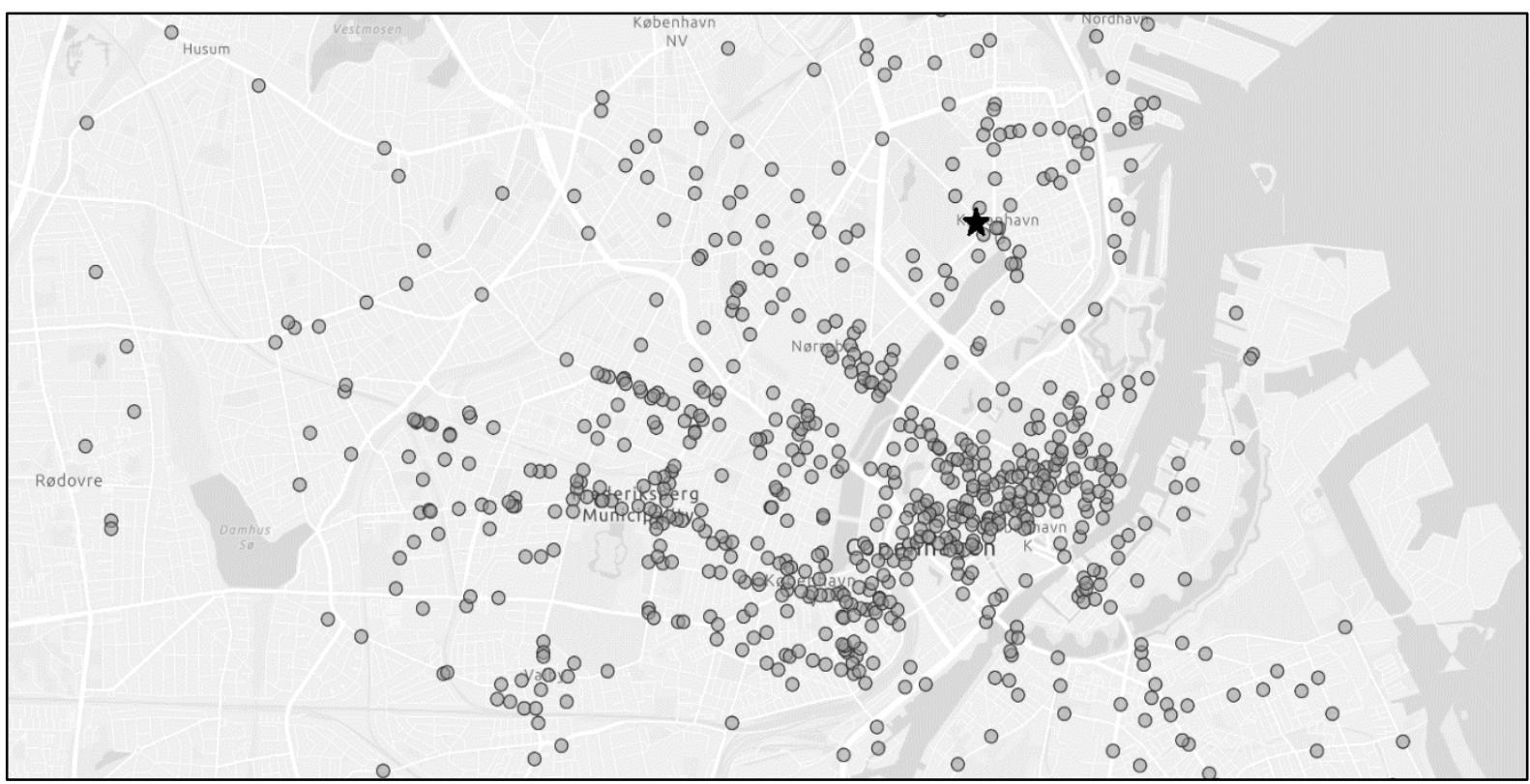

Figure 1: Customer network in Copenhagen (the distribution centre is marked with the star symbol while circles represent destination points).

- Speed calculated for 8 am is mapped to simulation periods between 7 am -10 am and $3 \mathrm{pm}$ - $5 \mathrm{pm}$, to simulate car movement through the network at rush hours (morning and afternoon).

- Speed calculated for 12 am is mapped to hours between 10 am - 3 pm to simulate the movement through the network when traffic conditions are regular.

- Speed calculated for $7 \mathrm{pm}$ is mapped to hours after $5 \mathrm{pm}$ to simulate movement through the network when the traffic is low.

We also query for the distance and travel time for the bicycle transportation mode (which is always constant, so we do it only once for each destination address).

Having in mind the KPIs described in previous section, we setup a simulation experiment with one independent variable, two moderating variables and two dependent variables to test whether significant differences in means of total deliveries and on-time delivery rates exist between different fleet types under different conditions. Variables and levels used are summarized and described in Table I.

Daily demand profiles (characterizing daily demand fluctuations) and driver availability are modelled as Poisson processes with intensity parameters adopted from previous studies $[15,24]$ and adjusted in consultation with domain experts. I.e. the values used in the simulation were sampled by using a specialized software package, from a Poisson distribution (Eq. (1)):

$$
P(k ; \lambda)=\frac{\lambda^{k} e^{-\lambda}}{k !}
$$

where $P(k ; \lambda)$ is the probability of observing $k$ events occurring within the observed interval and $\lambda$ is the process intensity parameter for that interval.

Adjustments were introduced in order to make the simulation more reflective of realworld demands that might be expected in the city of Copenhagen, and were based on prior experience of experts who work (or have worked) with companies providing delivery services. These companies often deal with small-parcel deliveries (such as consumer electronics or documents) and are thus relevant for our study. Even though there is a lot of variance in terms of the number of orders received throughout the day - that cannot be simply captured by a few distinct scenarios since there is a lot of variability between days due to 
seasonality, retailer campaigns, holidays, etc. - two representative profiles to characterize the demand were suggested by the experts. "Low" profile represents the arrival of delivery orders when the day is considered "slow' (i.e. there is low demand for delivery services). "Actual" profile represents the arrival of orders on a typical day. For both of them, it can be seen that there is an increase in demand after the first few hours of the day (which are reflective of people commuting to work and/or just beginning their work day) followed by a drop during lunch hours, which is in turn followed by a slight increase in demand for a few hours prior to it finally dropping towards the end of the day. "Uniform" profile is an attempt to model the demand as being uniform over the entire day, by setting the demand parameters to a value that is deemed reasonable given the experience of experts. Poisson process intensity parameter values used for the distribution of requests for delivery $\left(\lambda_{r}\right)$ and the number of crowdsourced drivers $(\lambda d)$ used for each specific hour of delivery-services' daily operations are shown in Table II.

Three different profiles have also been devised to simulate different scenarios that typically occur in terms of the time windows in which the couriers have to make the delivery. They have been modelled by discrete empirical distributions, which provide the probability that an incoming request will be placed with a 1-hr, 2-hr, 4-hr or 8-hr delivery window. The profiles devised by domain experts and considered in our study are: Flex $(10 \%, 30 \%, 40 \%$, $20 \%)$, Same Day (0 \%, $0 \%, 0 \%, 100 \%)$ and Standard (30\%, $40 \%, 20 \%, 10 \%)$. The same day ("Same Day") and standard ("Standard") scenarios model the use cases in which the delivery service allows the users to select only same-day delivery or any of the four delivery windows we are considering. "Flex" is modelling a service akin to AmazonFlex, where only same-day delivery is guaranteed, but customers are allowed to select a shorter delivery window.

Finally, to take into account the fact that crowdsourced drivers can choose at the end of each delivery whether they wish to make another one or not, new job acceptance probability is set to $75 \%$, which is in line with previous studies [15].

Table I: Summary and description of variables used in the simulation.

\begin{tabular}{|l|l|l|l|}
\hline \multicolumn{1}{|c|}{ Variable } & \multicolumn{1}{c|}{ Type } & \multicolumn{1}{c|}{ Definition } & \multicolumn{1}{c|}{ Measure } \\
\hline Fleet type & Independent & $\begin{array}{l}\text { Three levels of crowdsourced fleets: } \\
\text { Bicycle, Car or Mixed }\end{array}$ & $\begin{array}{l}\text { Bicycle - 100\% bicycles } \\
\text { Car - 100\% cars } \\
\text { Mixed - 50\% cars and 50\% } \\
\text { bicycles }\end{array}$ \\
\hline $\begin{array}{l}\text { Time window } \\
\text { distribution }\end{array}$ & Moderating & $\begin{array}{l}\text { The combination of 1-hr, 2-hr, 4-hr and } \\
\text { 8-hr time window requests for same-day } \\
\text { delivery services }\end{array}$ & $\begin{array}{l}\text { Three combinations of 1-hr, 2- } \\
\text { hr, 4-hr and 8-hr delivery } \\
\text { windows: Standard, Flex, and } \\
\text { Same Day }\end{array}$ \\
\hline $\begin{array}{l}\text { Daily demand } \\
\text { profile }\end{array}$ & Moderating & $\begin{array}{l}\text { The arrival rates of orders throughout the } \\
\text { workday that follow one of three profiles }\end{array}$ & $\begin{array}{l}\text { Three profiles: Uniform, Low, } \\
\text { Actual }\end{array}$ \\
\hline $\begin{array}{l}\text { Total } \\
\text { deliveries } \\
\text { made }\end{array}$ & Dependent & $\begin{array}{l}\text { A measure of logistics effectiveness } \\
\text { indicating how many deliveries are made } \\
\text { in each scenario }\end{array}$ & $\begin{array}{l}\text { Total number of deliveries } \\
\text { made }\end{array}$ \\
\hline $\begin{array}{l}\text { On-time } \\
\text { delivery rate }\end{array}$ & Dependent & $\begin{array}{l}\text { A measure of logistics' effectiveness } \\
\text { indicating how many deliveries are made } \\
\text { within the assigned time window relative } \\
\text { to the total number of deliveries made }\end{array}$ & $\begin{array}{l}\text { Number of on-time deliveries } \\
\text { divided by the total number of } \\
\text { deliveries made }\end{array}$ \\
\hline
\end{tabular}


Table II: Poisson process intensity parameters for daily demand profiles and crowdsourced drivers supply.

\begin{tabular}{|l|c|c|c|c|c|c|c|c|c|c|c|c|}
\hline \multicolumn{10}{|c|}{ Simulation hour } \\
\hline & 1 & 2 & 3 & 4 & 5 & 6 & 7 & 8 & 9 & 10 & 11 & 12 \\
\hline \multicolumn{10}{|c|}{ Daily demand profiles delivery requests per minute $(\lambda r)$} \\
\hline Low & 0.55 & 0.55 & 0.55 & 0.7 & 0.7 & 0.7 & 0.1 & 0.1 & 0.4 & 0.4 & 0.1 & 0.1 \\
\hline Actual & 0.75 & 0.75 & 0.75 & 1.1 & 1.1 & 1.1 & 0.25 & 0.25 & 0.4 & 0.4 & 0.1 & 0.1 \\
\hline Uniform & 0.55 & 0.55 & 0.55 & 0.55 & 0.55 & 0.55 & 0.55 & 0.55 & 0.55 & 0.55 & 0.55 & 0.55 \\
\hline \multicolumn{10}{|c|}{ Crowdsourced drivers supply - number of drivers available per minute $(\lambda d)$} & \\
\hline Drivers & 0.15 & 0.18 & 0.18 & 0.19 & 0.2 & 0.2 & 0.22 & 0.2 & 0.18 & 0.16 & 0.16 & 0.13 \\
\hline
\end{tabular}

\section{SIMULATION}

The simulation configuration and flow used are illustrated in Fig. 2. Within each iteration, work days of the week (Monday $=1$ through Friday $=5$ ) are considered, as most courier services do not operate during weekends (or make deliveries for an additional fee). For each day, a 12-hour interval ( 7 am to $7 \mathrm{pm}$ ) is used, which has intentionally been made longer than the standard daily working hours in most of the western countries (i.e. 9 am to $5 \mathrm{pm}$ ) to account for the specifics of the workplace culture in Denmark (flexible working hours) [25].

The simulation step is set to one minute, which allows for the correct modelling of drivers' movement through the customer network and taking into account dynamic traffic conditions pertinent to different days, as well as different times of the day. For each level of the independent and moderating variables, the simulation is repeated 25 times, each run comprising 30 iterations. This results in 101,250 total days simulated.

Conceptual model validation, computerized model verification and operational validation of the simulation have been performed by employing techniques described in [26]. In particular, we first implemented the simulation flow depicted in Fig. 2 in Python, where we leveraged standard modules optimized for numerical calculations and sampling wherever appropriate (e.g. Numpy). Domain experts not involved in the research were consulted to ensure the face validity of the model. We applied tracing and observation techniques to ensure that the behaviour of the model matched expectations. E.g. when delivery requests per minute were increased while keeping the driver supply constant, the size of the orders queue also increased. We also verified parameter variation sensitivity by inspecting the model output under different configurations of input parameters. E.g. increasing or decreasing On-time delivery rates when the drivers supply was increased or decreased respectively. Finally, we made sure the model was internally valid by observing low variability of the dependent variables' values across different runs.

\section{RESULTS}

After all the simulation runs have been completed, we calculated the mean values for total deliveries and on-time deliveries within each run. We then calculated the standard deviation across the runs. These results are shown in Table III.

To test whether differences in observed means of dependent variables are statistically significant, one-way ANOVA was performed for each level (i.e. profile) of moderating variables. 


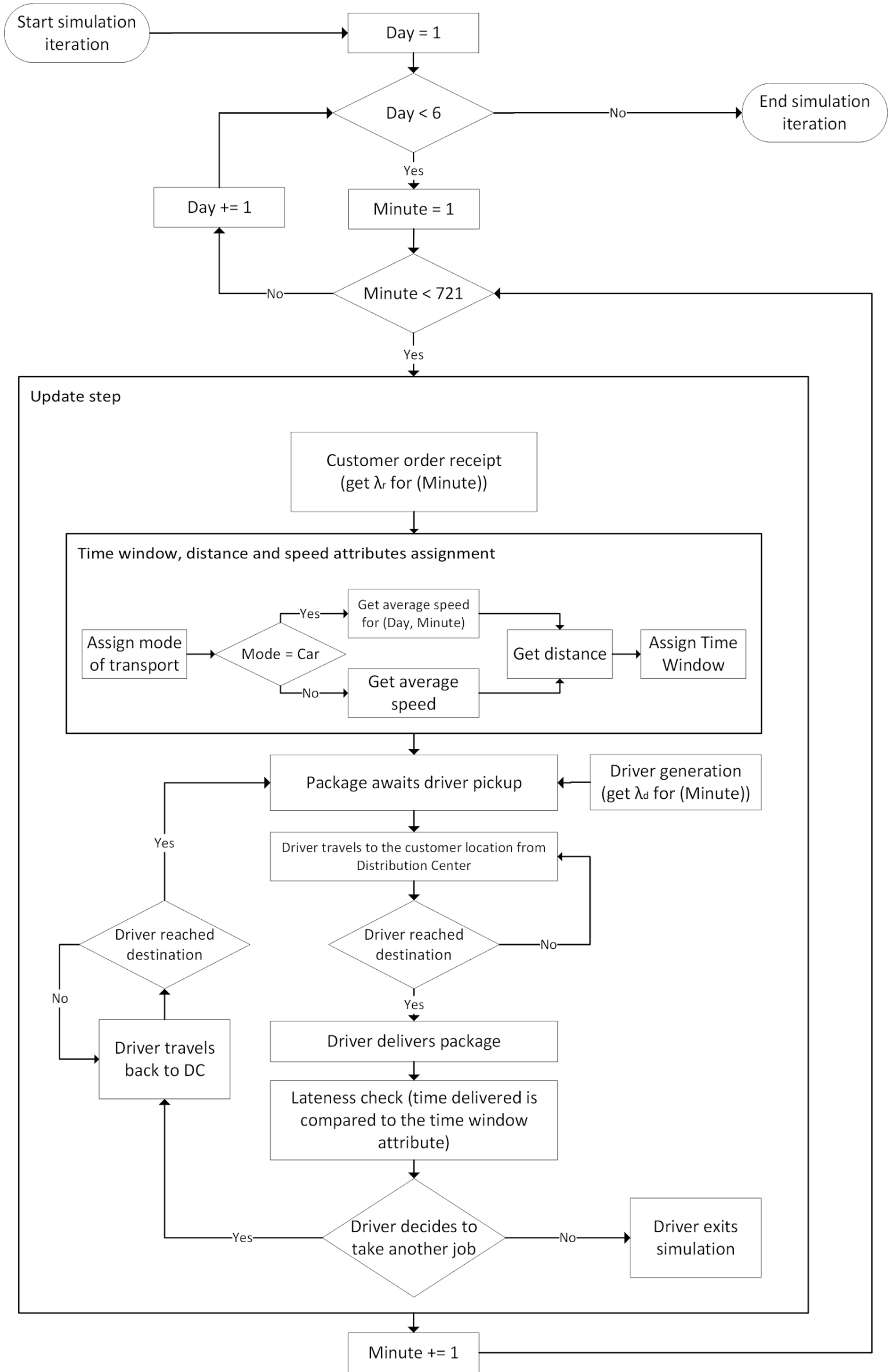

Figure 2: Simulation flow. 
Shapiro-Wilk test on each dependent variable confirmed that the data is normally distributed, which was additionally verified by visual inspection of normality plots. Even though the visual inspection of residuals suggested that assumption of homogenous variance is not violated, Levene test for equality of variances failed to confirm this for some of the groups. However, given that one-way ANOVA is quite robust to slight violations of normality and homogenous variance assumptions - especially when samples are of equal size [27] - we proceeded with post-hoc analysis to determine where the differences in means are. To this end, we utilized Tukey's HSD.

Table III: Simulation summary statistics.

\begin{tabular}{|c|c|c|c|c|c|c|}
\hline \multirow{2}{*}{ Variable } & \multirow{2}{*}{ Profile } & \multirow{2}{*}{ Fleet type } & \multicolumn{2}{|c|}{ Total deliveries } & \multicolumn{2}{|c|}{$\begin{array}{c}\text { On-time delivery } \\
\text { rate }(\%)\end{array}$} \\
\hline & & & Mean & Std & Mean & Std \\
\hline \multirow{9}{*}{ Time Window } & \multirow{3}{*}{ Flex } & Bicycles & 297.45 & 1.81 & 87.73 & 0.41 \\
\hline & & Cars & 276.75 & 1.33 & 82.24 & 0.39 \\
\hline & & Mixed & 288.45 & 1.11 & 85.32 & 0.28 \\
\hline & \multirow{3}{*}{ Standard } & Bicycles & 254.06 & 2.01 & 74.94 & 0.56 \\
\hline & & Cars & 222.44 & 2.31 & 66.13 & 0.72 \\
\hline & & Mixed & 239.81 & 2.02 & 70.94 & 0.53 \\
\hline & \multirow{3}{*}{ Same Day } & Bicycles & 338.87 & 0.88 & 100.00 & 0.00 \\
\hline & & Cars & 336.43 & 0.85 & 100.00 & 0.00 \\
\hline & & Mixed & 337.76 & 0.92 & 100.00 & 0.00 \\
\hline \multirow{9}{*}{$\begin{array}{l}\text { Daily } \\
\text { Demand }\end{array}$} & \multirow{3}{*}{ Low } & Bicycles & 243.63 & 0.83 & 92.22 & 0.33 \\
\hline & & Cars & 231.37 & 0.80 & 87.58 & 0.33 \\
\hline & & Mixed & 238.18 & 0.73 & 90.17 & 0.31 \\
\hline & \multirow{3}{*}{ Actual } & Bicycles & 283.26 & 1.42 & 76.53 & 0.36 \\
\hline & & Cars & 260.44 & 1.75 & 71.02 & 0.44 \\
\hline & & Mixed & 272.44 & 1.40 & 73.88 & 0.36 \\
\hline & \multirow{3}{*}{ Uniform } & Bicycles & 363.49 & 1.28 & 95.00 & 0.26 \\
\hline & & Cars & 343.81 & 2.54 & 90.85 & 0.60 \\
\hline & & Mixed & 355.40 & 1.91 & 93.28 & 0.36 \\
\hline
\end{tabular}

There were statistically significant differences $(p<0.05)$ between all group means within identified profiles, as determined by one-way ANOVA - with the exception of on-time delivery rate for Same Day deliveries profile. In post-hoc analysis, Tukey's HSD revealed that significant differences existed between all tested groups (at $p<0.05$ level), again with the exception of on-time delivery rate for the Same Day profile. Differences in means between groups with $95 \%$ confidence intervals (returned by Tukey's HSD) with respect to total deliveries and on-time delivery rates are shown in Fig. 3.

Obtained results indicate that there are statistically significant differences in fleet logistics' effectiveness between the simulated crowdsourced fleets, which are affected by both daily demand dynamics (supporting H1) and levels of services offered (supporting H2). 
a) Total deliveries

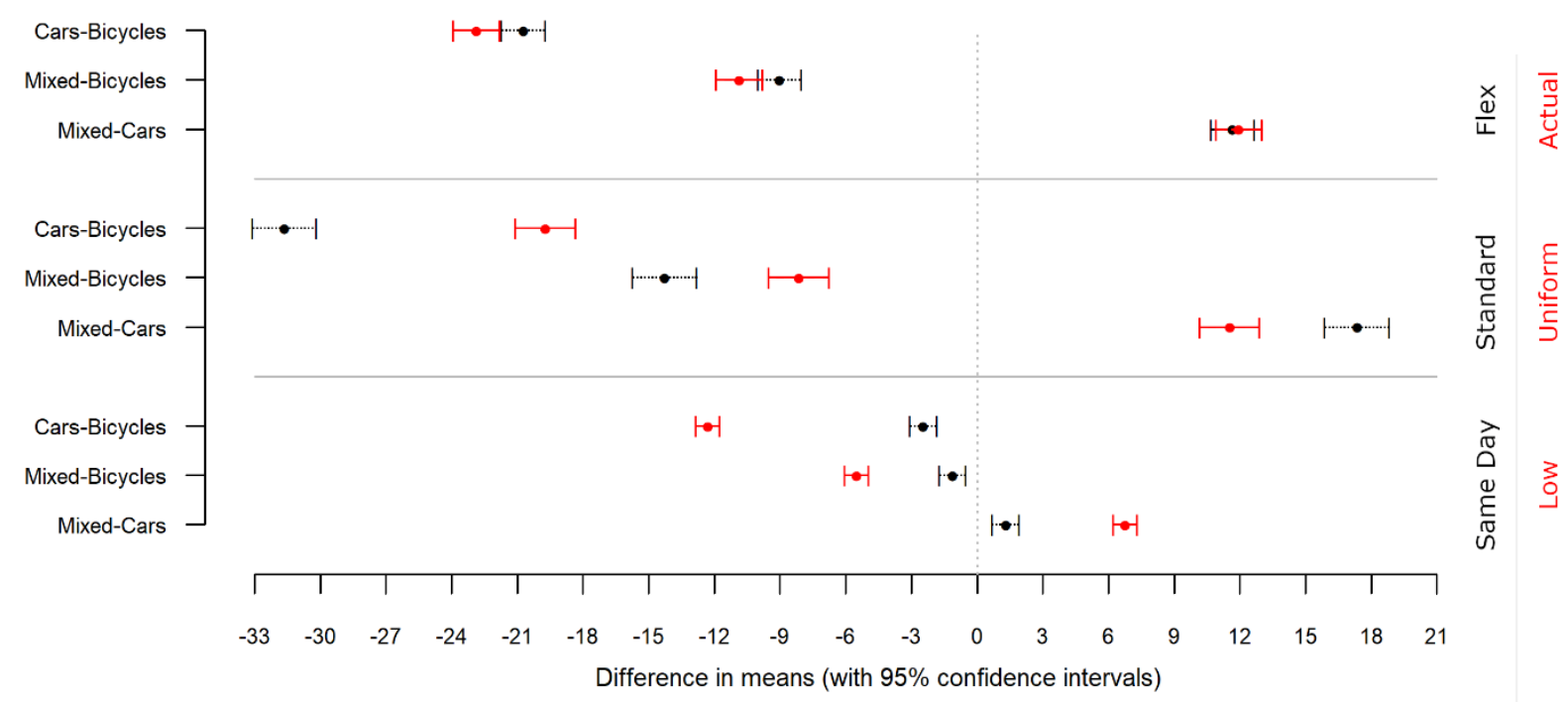

$\vdash \cdot-1$ Daily demand $\quad+\cdot-1$ Time window

b) On-time delivery rates (\%)

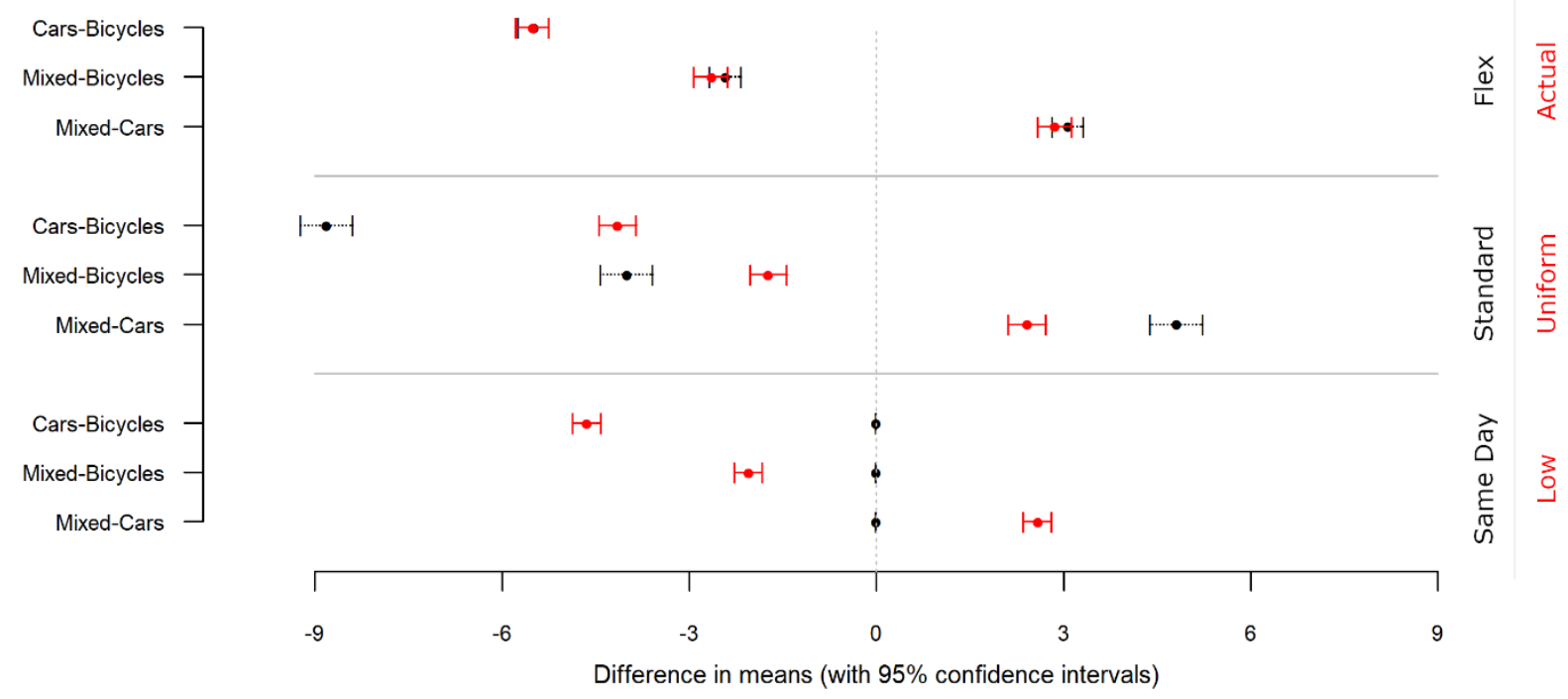

Figure 3: Results of post-hoc analysis (Tukey's HSD) for: a) total deliveries and b) on-time delivery rates.

Introduction of bicycles into the fleets leads to significant increase in effectiveness (both in terms of total deliveries and the rate of deliveries made on time), with the purely bicyclebased fleet being the most effective. Bicycle-based fleet was most effective across all of the simulated profiles, with the most noticeable gap within Standard daily demand $(13.3 \%$ more total deliveries and $12.5 \%$ higher on-time delivery rate) and Actual time-window (8.4\% more total deliveries and $7.5 \%$ higher on-time delivery rate) scenarios, which most closely resemble a realistic use case.

For same day deliveries, any of the three examined types of fleet is able to achieve total effectiveness in terms of making the delivery on time, as the time window is long enough for any type of vehicle to be able to meet the delivery deadline. This is also a scenario where there is the smallest difference between the three delivery solutions in terms of the total number of deliveries made, with the best, bicycle-based, solution yielding only a single delivery more (out of 330+) than the worst, car-based, on average. 
In all simulated scenarios, mixed fleet (consisting of $50 \%$ bicycle couriers and $50 \%$ car drivers) consistently showed results that are midway between the performance of car and bicycle fleets, suggesting that, under the constraints of our study, any fleet would benefit from the introduction of bicycle couriers. This suggests that, although the bicycles are inherently a slower mode of transport, in a city amenable to cyclists, they benefit from not being affected by traffic conditions so much that they win out in the end.

The differences in performance between the car-based and bicycle-based solutions when the demand is low or uniformly distributed are not as pronounced (approximately $5 \%$ for both total deliveries and on-time delivery rate), as both scenarios allow any fleet to maximize the performance measures used. This is especially true for the uniform demand scenario, where the cars are not penalized as much by the fluctuating traffic conditions and all fleets make use of the stable demand conditions to make the largest total number of deliveries.

The flexible (Flex) daily demand profile, perhaps unsurprisingly, lead to larger differences in performance $(7.2 \%$ and $6.5 \%$ in total deliveries and on-time delivery rate, respectively) than the same-day scenario, but not as pronounced as in the standard case. This is in accordance to the fact that the delivery-window distribution produced by the domain experts leans toward larger windows (4-hour and 8-hour), which are less challenging for any fleet to meet than the shorter time windows comprising the larger part of the distribution in the Standard profile, but still more tasking than the largest 8-hour delivery window which is the sole requirement in the same-day delivery profile.

\section{CONCLUSION}

We studied the performance for three types of crowdsourced delivery fleets likely to be used in an urban setting, differing in the mode of transport the couriers use: bicycles, cars or mixed. The fleet logistic effectiveness, characterized by the total number of deliveries made and the rate of deliveries made on time, was simulated using models parametrized by travel time projections provided by Google Directions, derived from real-world traffic data collected for the city of Copenhagen in Denmark. Thus, our simulation closely resembles real-world traffic conditions in a city with developed cycling infrastructure and takes into account the variations in the speed of couriers.

Our study showed that introduction of bicycle-based crowdsourced couriers lead to statistically significant improvements in the fleet performance, when single-parcel urban delivery scenarios are regarded within a city that has a developed cycling infrastructure. This has several practical implications.

First, the cost of deliveries could be lowered as there are no fuel or parking expenses associated with this mode of transport (and bicycle maintenance is quite low). This directly translates to more competitive prices that could be offered by companies relying on crowdsourced bicycle fleets.

Secondly, a significantly larger courier base could be reached, as no driver's license or extensive training is required to use this mode of transport [28]. In addition, bicycles are far more affordable and their number often exceeds that of cars in urban areas [23].

Thirdly, positive environmental impact of bicycle-based fleets is in line with initiatives to reduce carbon-dioxide emissions as well as with those to completely discontinue sales of cars powered by fossil fuel by 2030 in some countries [29].

Finally, introducing bicycle-based crowdsourced fleets for last-mile delivery would contribute to the fulfilment of EU Cycling Strategy, which envisions the growth of jobs in the cycling economy from 650,000 in 2017 to 875,000 by 2030 [30].

The biggest limitation of our study is the assumption that each vehicle can only carry a single parcel, not larger than what a cyclist can carry. Although this is not unreasonable in 
many modern scenarios where express delivery is used, such as food delivery, documents etc., it effectively eliminates one of the two major advantages of cars as delivery vehicles: the ability to carry larger loads. Combined with the effect of traffic congestion, which plagues the cars, but not the bicycles, it is not surprising that the results of our study favour the inclusion of bicycle couriers into a delivery fleet.

Our study is also limited by the constraint that there are no detours and that the couriers can only carry a single package at a time. While this is usually so in the practical delivery services done by bicycle and common for very short delivery time windows, it is probably a stretch for the same-day scenario. More empirical data is required to validate this assumption. Obtaining such data is planned for a future study.

Several other future research directions naturally emerge from the results obtained. For example, it would be interesting to compare the performance of different types of crowdsourced fleets in cities with varying levels of cycling-infrastructure development or different traffic pattern profiles, to see how well our results generalize. Measuring the effects of seasons (as well as of weather conditions) on cyclist-courier availability and the performance of bicycle-based crowdsourced fleets is another question that needs to be addressed in order to provide courier companies with more robust inputs for operational planning. Also, understanding the attitude of crowdsourced cyclist-couriers towards making door-to-door and multi-parcel deliveries is something to be investigated, as is the possibility of using package handover between couriers using different modes of transport to optimize delivery time.

\section{REFERENCES}

[1] Wang, C. L.; Li, S. W. (2018). Hybrid fruit fly optimization algorithm for solving multicompartment vehicle routing problem in intelligent logistics, Advances in Production Engineering \& Management, Vol. 13, No. 4, 466-478, doi:10.14743/apem2018.4.304

[2] Setzke, D. S.; Pfluegler, C.; Schreieck, M.; Fröhlich, S.; Wiesche, M.; Krcmar, H. (2017). Matching drivers and transportation requests in crowdsourced delivery systems, Proceedings of the $23^{\text {rd }}$ Americas Conference on Information Systems (AMCIS), 1-10

[3] Wu, D. Q.; Dong, M.; Li, H. Y.; Li, F. (2016). Vehicle routing problem with time windows using multi-objective co-evolutionary approach, International Journal of Simulation Modelling, Vol. 15, No. 4, 742-753, doi:10.2507/IJSIMM15(4)CO19

[4] Feng, X.; Ruan, Z.; Zhu, X.; Zhang, L. (2018). Multi-objective transport network design with a reversible simulated annealing algorithm, Advances in Production Engineering \& Management, Vol. 13, No. 4, 479-491, doi:10.14743/apem2018.4.305

[5] Giret, A.; Carrascosa, C.; Julian, V.; Rebollo, M.; Botti, V. (2018). A crowdsourcing approach for sustainable last mile delivery, Sustainability, Vol. 10, No. 12, 45-63, doi:10.3390/su10124563

[6] Edwards, J. B.; McKinnon, A. C.; Cullinane, S. L. (2010). Comparative analysis of the carbon footprints of conventional and online retailing, International Journal of Physical Distribution \& Logistics Management, Vol. 40, No. 1-2, 103-123, doi:10.1108/09600031011018055

[7] Gatta, V.; Marcucci, E.; Nigro, M.; Serafini, S. (2019). Sustainable urban freight transport adopting public transport-based crowdshipping for B2C deliveries, European Transport Research Review, Vol. 11, No. 1, 13 pages, doi:10.1186/s12544-019-0352-x

[8] PWC. 2018 Global Consumer Insights Survey, from https://www.pwc.com/gx/en/industries/ consumer-markets/consumer-insights-survey.html, accessed on 22-02-2019

[9] Rouges, J.-F.; Montreuil, B. (2014). Crowdsourcing delivery: new interconnected business models to reinvent delivery, Proceedings of the $1^{\text {st }}$ International Physical Internet Conference, 119

[10] Estelles-Arolas, E.; Gonzalez-Ladron-De-Guevara, F. (2012). Towards an integrated crowdsourcing definition, Journal of Information Science, Vol. 32, No. 2, 189-200, doi: $\underline{10.1177 / 0165551512437638}$ 
[11] Pedersen, J.; Kocsis, D.; Tripathi, A.; Tarrell, A.; Weerakoon, A.; Tahmasbi, N.; Xiong, J.; Deng, W.; Oh, O.; de Vreede, G.-J. (2013). Conceptual foundations of crowdsourcing: a review of IS research, Proceedings of the $46^{\text {th }}$ Hawaii International Conference on System Sciences, 579-588, doi:10.1109/HICSS.2013.143

[12] Cramer, J.; Krueger, A. (2016). Disruptive change in the taxi business: the case of Uber, American Economic Review, Vol. 106, No. 5, 177-182, doi:10.3386/w22083

[13] Kittur, A.; Chi, E. H.; Suh, B. (2008). Crowdsourcing user studies with Mechanical Turk, Proceedings of the 2008 SIGCHI Conference on Human Factors in Computing Systems, 453-456, doi: $10.1145 / 1357054.1357127$

[14] Craig, D. C. (1996). Extensible Hierarchical Object-Oriented Logic Simulation with an Adaptable Graphical User Interface, PhD Thesis, Memorial University of Newfoundland, St. John's

[15] Castillo, V. E.; Bell, J. E.; Rose, W. J.; Rodrigues, A. M. (2017). Crowdsourcing last mile delivery: strategic implications and future research directions, Journal of Business Logistics, Vol. 39, No. 1, 7-25, doi:10.1111/jbl.12173

[16] Rajapakshe, T.; Dawande, M.; Gavirneni, S.; Sriskandarajah, C.; Rao Panchalavarapu, P. (2013). Dedicated transportation subnetworks: design, analysis, and insights, Production and Operations Management, Vol. 23, No. 1, 138-159, doi:10.1111/poms.12029

[17] Hossain, M.; Kauranen, I. (2015). Crowdsourcing: a comprehensive literature review, Strategic Outsourcing: An International Journal, Vol. 8, No. 1, 2-22, doi:10.1108/SO-12-2014-0029

[18] Fugate, B. S.; Mentzer, J. T.; Stank, T. P. (2011). Logistics performance: efficiency, effectiveness, and differentiation, Journal of Business Logistics, Vol. 31, No. 1, 43-62, doi:10.1002/j.2158-1592.2010.tb00127.x

[19] Boyer, K. K.; Prud'homme, A. M.; Chung, W. (2011). The last mile challenge: evaluating the effects of customer density and delivery window patterns, Journal of Business Logistics, Vol. 30, No. 1, 185-201, doi:10.1002/j.2158-1592.2009.tb00104.x

[20] Sorkun, M. F. (2019). Factors that impact the logistics service performance in online marketplaces, Journal of Yasar University, Vol. 14, No. 54, 152-167

[21] Agatz, N. A. H.; Fleischmann, M.; van Nunen, J. A. E. E. (2008). E-fulfillment and multichannel distribution: a review, European Journal of Operational Research, Vol. 187, No. 2, 339356, doi:10.1016/j.ejor.2007.04.024

[22] Hu, C.; Lu, J.; Liu, X.; Zhang, G. (2018). Robust vehicle routing problem with hard time windows under demand and travel time uncertainty, Computers \& Operations Research, Vol. 94, 139-153, doi:10.1016/j.cor.2018.02.006

[23] Petersen Weihe, C. (2017). Copenhagen City of Cyclists - facts and figures 2017, Cycling Embassy of Denmark, København

[24] Gendreau, M.; Guertin, F.; Potvin, J.-Y.; Seguin, R. (2006). Neighborhood search heuristics for a dynamic vehicle dispatching problem with pick-ups and deliveries, Transportation Research Part C: Emerging Technologies, Vol. 14, No. 3, 157-174, doi:10.1016/j.trc.2006.03.002

[25] Danish Ministry of Employment. Workplace Culture in Denmark, from https://www.workindenmark.dk/Working-in-DK/Workplace-culture-in-Denmark, accessed on 2702-2019

[26] Sargent, R. G. (2013). Verification and validation of simulation models, Journal of Simulation, Vol. 7, No. 1, 12-24, doi: $10.1057 /$ jos.2012.20

[27] Pallant, J. (2013). SPSS Survival Manual, $5^{\text {th }}$ edition, McGraw-Hill Education, New York

[28] Transport of London. Cycle Freight in London: a Scoping Study, from https://8freight.com/cmsimages/cycle-as-freight-may-2009.pdf, accessed on 03-03-2019

[29] Danish Government. Stop Selling New Petrol and Diesel-fuelled Cars by 2030, from https://www.thelocal.dk/20181004/stop-selling-new-petrol-and-diesel-fuelled-cars-by-2030danish-government, accessed on 04-03-2019

[30] European Cyclists' Federation. Recommendations for Delivering Green Growth and an Effective Mobility System in 2030, from https://ecf.com/sites/ecf.com/files/EUCS_Summary_small_ file.pdf, accessed on 04-03-2019 